\title{
Association of Epstein-Barr virus infection with allogeneic hematopoietic stem cell transplantation in patients in Portugal
}

\author{
JOANA MARINHO-DIAS ${ }^{1-3}$, INÊS BALDAQUE ${ }^{1}$, CARLOS PINHO-VAZ $^{4}$, LUÍS LEITE ${ }^{4}$, ROSA BRANCA $^{4}$, \\ FERNANDO CAMPILHO ${ }^{4}$, ANTÓNIO CAMPOS Jr ${ }^{4}$, RUI MEDEIROS ${ }^{1-3,5}$ and HUGO SOUSA ${ }^{1,2}$ \\ ${ }^{1}$ Virology Service; ${ }^{2}$ Molecular Oncology and Viral Pathology Group, Portuguese Oncology Institute of Porto, $4200-072$ Porto; \\ ${ }^{3}$ Abel Salazar Institute for The Biomedical Sciences (ICBAS), University of Porto, 4050-313 Porto; \\ ${ }^{4}$ Bone Marrow Transplantation Unit, Portuguese Oncology Institute of Porto, 4200-072 Porto; \\ ${ }^{5}$ Research Department, Portuguese League Against Cancer (LPCC-NRNorte), 4200-172 Porto, Portugal
}

Received November 30, 2017; Accepted July 5, 2018

DOI: $10.3892 / \mathrm{mmr} .2018 .9794$

\begin{abstract}
The identification of patients at higher risk of developing Epstein-Barr virus (EBV) infection in hematopoietic stem cell transplants (HSCT) is useful for the prevention of EBV-associated diseases A prospective observational study was developed that included 40 patients (27 male and 13 females, with mean age of $32.2 \pm 1.5$ years old) undergoing allogeneic-HSCT between January and December 2015. EBV was examined in whole blood samples collected during routine procedures at day (D)+30, D +60, $+90, \mathrm{D}+120, \mathrm{D}+150$ and D+180 post-transplant. EBV was detected, at least once during the follow-up period in $70.0 \%$ of our patients. Results indicated that patients with unrelated donors had increased risk of developing EBV infection at $\mathrm{D}+60$ and $\mathrm{D}+150(\mathrm{OR}=3.9, \mathrm{P}=0.058 ; \mathrm{OR}=8.0, \mathrm{P}=0.043$; respectively). Moreover, myeloablative conditioning $(\mathrm{OR}=4.3, \mathrm{P}=0.052)$, anti-thymocyte globulin use $(\mathrm{OR}=12.0$, $\mathrm{P}=0.030)$ and graft-vs.-host disease $(\mathrm{OR}=6.7, \mathrm{P}=0.032)$ were associated with EBV infection at D+60, D+150 and D+90, respectively. In our series, none of these patients developed post-transplant lymphoproliferative disease. To the best of our knowledge, the present study is the first study to report EBV infection in patients undergoing aHSCT from Portugal. The study revealed that EBV infection is associated with different factors. These findings provide evidence towards the identification of high-risk patients for EBV-infection and associated disease.
\end{abstract}

Correspondence to: Dr Joana Marinho-Dias or Professor Hugo Sousa, Virology Service, Portuguese Oncology Institute of Porto, Rua Dr António Bernardino de Almeida, 4200-072 Porto, Portugal

E-mail: joana_marinho_dias@hotmail.com

E-mail: hugomls@gmail.com

Key words: Epstein-Barr virus, hematopoietic stem cell transplant, post-transplant lymphoproliferative disease, graft-vs.-host disease

\section{Introduction}

Hematopoietic stem cell transplants (HSCT) is an effective therapy in the treatment of hematological malignancies such as leukemias and lymphomas (1). The regimens required for transplant produce profound immune deficiency in the early period after transplantation (2). Conditioning regimens include: Myeloablative (MAC) and reduced intensity conditioning (RIC). MACs include concomitant or single use of alkylating agents, such as cyclophosphamide (Cy) and busulfan (Bu), while RICs are mainly performed with fludarabine (Flu) or low doses of total body irradiation $(\mathrm{TBI})(3,4)$. Choice of conditioning depends on patient's age, underlying disease, relevant comorbidities and type of donor. These regimens are related to several risks such as infections, graft-vs.-host disease (GVHD) and post-transplant lymphoproliferative disorder (PTLD) (5). GVHD occurs in approximately $40-90 \%$ of transplanted patients (6). ATG seems to be effective in GVHD prophylaxis, and is related to reduced rates of relapses and infections in adults who undergo bone marrow (BM) or peripheral blood stem cells (PBSC) transplant (7).

Rates of mortality after HSCT often reach up to $50.0 \%$ (5). Some studies describe that intensive conditioning regimens are associated with reduction of tumor relapses, although it might simultaneously increase the transplant-related mortality rates, including the mortality of infections (4).

Epstein-Barr virus (EBV) is a ubiquitous Human Herpes virus and infects $50-89 \%$ of children and remains latent, in memory B cells, of $\sim 90 \%$ of adults (8). Viral infections are known to be a major cause of morbidity and mortality in patients undergoing HSCT and Herpes virus are known to be among the most common viral infections in these patients (5). The iatrogenic suppression of T-cell with the immunosuppression of the transplant regimens, allows the proliferation of infected $\mathrm{B}$ cells (9). EBV is one of the most important viruses in transplanted patients, and monitoring of EBV DNA in peripheral blood is routinely performed in several transplant centers, since these patients have a higher-risk of developing complications (9-13).

This study aims to analyze the impact of the different characteristics of allogeneic-HSCT (aHSCT) patients and correlate with the development of EBV infection. 


\section{Materials and methods}

Type of study and study participant. A prospective follow-up study was performed with 40 consecutive patients who underwent aHSCT at the Bone Marrow Transplant Service of Portuguese Oncology Institute of Porto (IPO Porto; Porto, Portugal) between January and December of 2015. Cases were selected randomly from the cohort of patients undergoing aHSCT. The study was approved by the local Ethical Committee and did not interfere with the routine procedures decided by clinicians. Clinical data was collected from individual clinical records and stored in a database with unique codification.

Sample processing. EBV detection is not routinely requested for all HSCT patients in our institution (only for high-risk), and therefore we have used samples collected during routine procedures for patients monitoring selected at 6 different times: $\mathrm{D}+30,+60,+90,+120,+150$ and +180 days after transplant. Samples were collected in EDTA-containing tubes and stored prior to processing.

Sample processing was performed at the Virology Service of IPO Porto. DNA was extracted by MagNA Pure Compact Nucleic Acid Isolation kit I (Roche, Germany). DNA/RNA quality was assessed by measuring the absorbance at 260/280 nm with NanoDrop 1000 Spectrophotometer v3.7 (Thermo Fischer Scientific, Inc., Wilmington, MA, USA).

EBV detection. EBV detection was performed with a real-time PCR protocol targeting EBV polymerase gene (EBV POL) as previously reported (14). Amplification was performed with the ABI PRISM 7300 Sequencer Detection System (Applied Biosystems, Foster City, CA, USA) and results were obtained by measuring the geometric increase of probe fluorescence during amplification and samples were considered positive when the exponential curve exceeded the cycle threshold line. All amplifications used positive and negative controls: As negative control, we used double distilled water in replacement of template DNA; and as positive control we have used samples from the External Quality Control panel for EBV used at the Virology Service. Results were independently analyzed by two of the authors and $10 \%$ of all samples were randomly selected and re-submitted to amplification to confirm the results.

Statistical analysis. Statistical analysis was performed with IBM $^{\circledR}$ SPSS Statistics 20 software (IBM Corp., Armonk, NY, USA) for Mac. Chi-square or Fisher's exact test with a $5 \%$ significance level were used to estimate odds ratio (OR) and the corresponding $95 \%$ confidence intervals (CIs) as a measure of association between the categorical variables and the risk of EBV infection. Cox proportional hazard models were used to assess the risk factors associated EBV infection. Kaplan-Meier with log-Rank test was used to calculate the association between EBV infection and post-transplant survival (OS).

\section{Results}

Clinical characteristics. This study included 40 patients, 27 males (67.5\%) and 13 females (32.5\%), with ages between 1 and 63 years-old (mean $32.2 \pm 1.5$, median 35 years old) who
Table I. Clinical characteristics of patients.

\begin{tabular}{lr}
\hline Characteristics & Number (\%) \\
\hline Age, median (range) years old & $32.2(1-63)$ \\
Sex, $\mathrm{n}(\%)$ & \\
Male & $27(67.5)$ \\
Female & $13(32.5)$ \\
Underlying disease, $\mathrm{n}(\%)$ & \\
Aplastic anemia & $3(7.5)$ \\
Acute leucemia & $23(57.5)$ \\
Chronic leucemia & $2(5.0)$ \\
Non-Hodgkin lymphoma & $1(2.5)$ \\
Multiple myeloma & $1(2.5)$ \\
Myelodysplastic/myeloproliferative syndrome & $7(17.5)$ \\
Others & $3(7.5)$ \\
Conditioning regimen, $\mathrm{n}(\%)$ & \\
BuCy & $4(10.0)$ \\
BuCy2 & $20(50.0)$ \\
Cy & $1(2.5)$ \\
FluBu & $10(25.0)$ \\
FluCy & $3(7.5)$ \\
FluMelf & $1(2.5)$ \\
ATG, $\mathrm{n}(\%)$ & \\
Yes & $20(50.0)$ \\
No & $20(50.0)$ \\
Type of donor, $\mathrm{n}(\%)$ & \\
Related & $19(47.5)$ \\
Mismatched/unrelated & $21(52.5)$ \\
Source of cells, $\mathrm{n}(\%)$ & \\
PBSC & $33(82.5)$ \\
BM & $5(12.5)$ \\
UCB & $2(5.0)$ \\
\hline B & \\
\hline
\end{tabular}

$\mathrm{Bu}$, busulfan; Cy, cyclophosphamide; Flu, fludarabine; Melf, Melphalan; ATG, anti-thymocyte globulin; PBSC, peripheral blood stem cells; BM, bone marrow; UCB, umbilical cord blood.

underwent aHSCT at our institution between January and December of 2015.

Table I demonstrates the characteristics of all patients. Briefly, patients were submitted to aHSCT due to different hematological malignancies, including aplastic anemia $(n=3)$, acute leukemia $(\mathrm{n}=23)$, chronic leukemia $(\mathrm{n}=2)$, non-Hodgkin lymphoma $(\mathrm{n}=1)$, multiple myeloma $(n=1)$, myelodysplastic/myeloproliferative syndrome $(n=7)$ and others, including primary immunodeficiency, myelofibrosis and severe combined immunodeficiency $(\mathrm{n}=3)$. Off the 40 patients submitted to aHSCT only one was being transplanted for the second time. When evaluating the donor-receptor relation, 21 patients had unrelated donors (52.5\%) and the remaining 19 had related donors (47.5\%). Regarding the HLA-match, only one patient received a graft from a HLA-mismatched donor. The source of cells for transplant was mainly from peripheral blood $(82.0 \%)$, while the remaining were from BM (13.0\%) and umbilical cord blood (5.0\%). MAC 


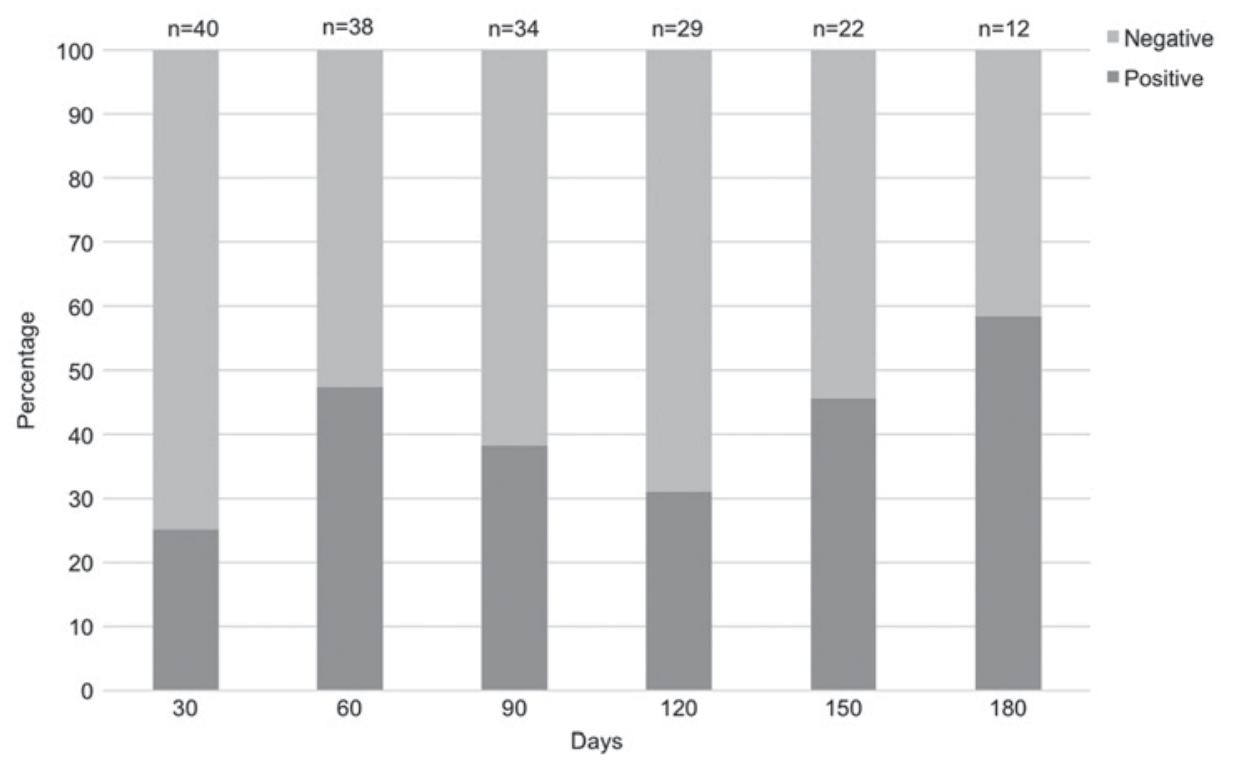

Figure 1. EBV infection at different times during post-transplant monitoring. EBV, Epstein-Barr virus.

conditioning was used in $24(60.0 \%)$ of our patients, with $\mathrm{Bu}$ and cyclophosphamide, as well as ATG which was used in 14 of these patients. Reduced intensity regimens were used in 16 patients with 6 of them receiving ATG. Patients with unrelated donors, except in one case, received ATG as part of GVHD prophylaxis. Prophylaxis for GVHD was performed for all patients (data not available for 2 patients). Acute GVHD (aGVHD) was observed in 21 patients, all of them with grade 2 or higher; while chronic GVHD (cGVHD) was present in 5 patients, 4 with evolution from aGVHD and only one with de novo cGVHD.

EBV and CMV serological status was described as: $\operatorname{IgM}$ positive and IgG negative/positive (active infection); IgM negative and $\operatorname{IgG}$ positive (past-infection); and $\operatorname{IgM}$ negative and IgG negative (susceptible). In our study, we found 3 patients were susceptible for EBV-primary infection, 1 patient had an active EBV-infection and 7 patients were susceptible of CMV-primary infection (data not shown).

EBV infection. The overall data reveal that $70 \%$ of patients were at least once positive during the follow-up period. Regarding the specific times of sample collection in our study, results showed the presence of EBV in 10/40 (25\%) at D+30, 18/38 $(47 \%)$ at $\mathrm{D}+60,13 / 34(38 \%)$ at $\mathrm{D}+90,9 / 29(31 \%)$ at $\mathrm{D}+120$, $10 / 22(45 \%)$ at $\mathrm{D}+150$, and $7 / 12(58 \%)$ at D+180 (Fig. 1).

The analysis of EBV DNA positivity (at least once positive) and its association with clinicopathological characteristics of patients is shown in Table II. The analysis according to sex seem to show that post-transplant EBV infection is more frequent in females $(\mathrm{OR}=8.33, \mathrm{P}=0.033)$. Despite not statistically significant, we have found that EBV infection is more frequent in patients with unrelated donors $(\mathrm{OR}=3.12, \mathrm{P}=0.112)$, engrafted with $\mathrm{PBSC}(\mathrm{OR}=2.00, \mathrm{P}=0.414)$, submitted to $\mathrm{MAC}$ conditioning regimen $(\mathrm{OR}=2.96, \mathrm{P}=0.121)$, using $\mathrm{ATG}$ in the conditioning regimen $(\mathrm{OR}=2.91, \mathrm{P}=0.135)$, and that developed aGVHD (OR=3.09, $\mathrm{P}=0.112)$. Despite we observe an increased prevalence of EBV in older patients, there was no statistically significant association regarding age (child vs. adults, or median age) $(\mathrm{P}>0.050)$. EBV serostatus prior to transplant does not seem to be related with the development of infection during the post-transplant period (data not shown).

The analysis of EBV infection at the different times during the follow-up period revealed different associations with clinicopathological data, despite not all with statistical significance. At D+60, EBV infection was associated with transplants from unrelated donors $(\mathrm{OR}=3.9, \mathrm{P}=0.058)$, with $\mathrm{MAC}$ conditioning $(\mathrm{OR}=4.3, \mathrm{P}=0.052)$ and use of $\mathrm{ATG}(\mathrm{OR}=3.6, \mathrm{P}=0.099)$, although, with no statistical significance; at D+90, development of GVHD was related a higher risk of infection $(\mathrm{OR}=6.7, \mathrm{P}=0.032)$; and finally, at $\mathrm{D}+150, \mathrm{EBV}$ infection was associated with unrelated donors $(\mathrm{OR}=8.0, \mathrm{P}=0.043)$, use of $\mathrm{ATG}(\mathrm{OR}=12.0, \mathrm{P}=0.030)$ and development of GVHD (OR=5.6, $\mathrm{P}=0.099)$. There was no significant association between age and EBV infection in different times (data not shown). The Cox regression analysis considering patients sex, type of donor, conditioning regimen, use of ATG and development of aGVHD, revealed an association of unrelated donor with $\mathrm{EBV}$ infection at $\mathrm{D}+150(\mathrm{HR}=8.8, \mathrm{P}=0.030)$.

Follow-up. None of these patients had clinical suspicion or development PTLD during follow-up. Of the 40 patients included in this study, 16 patients have deceased, 6 are alive with evidence of disease and 18 are alive without evidence of disease. Cumulative survival was evaluated by performing a Kaplan-Meier plot and estimated survival time was approximately 476 \pm 58.7 days (data not shown).

Analysis of EBV-infection impact on overall survival (OS) is shown in Fig. 2. The impact of EBV infectionon OS, in different times, is shown in Fig. 3. Results suggest that EBV positivity at D+90 days and D+180 may be associated with increased mortality $(\mathrm{P}=0.095,303.3$ vs. 593.2 days and $\mathrm{P}=0.097,367.0$ vs. 679.5 , respectively).

\section{Discussion}

aHSCT is an option for the treatment of hematological malignancies and these patients are submitted to pre-transplant treatments that reduce significantly the immune system to avoid rejection 
Table II. Analysis of EBV infection among allogeneic hematological stem cell transplant recipients.

\begin{tabular}{|c|c|c|c|}
\hline Variable & EBV infection n $(\%)$ & P-value & OR $(95 \% \mathrm{CI})$ \\
\hline \multicolumn{4}{|l|}{ Sex } \\
\hline Male $(n=27)$ & $16(59.3)$ & \multirow[t]{2}{*}{0.033} & \multirow[t]{2}{*}{$8.33(0.93-100)$} \\
\hline Female $(\mathrm{n}=13)$ & $12(92.3)$ & & \\
\hline \multicolumn{4}{|l|}{ Stem cell source } \\
\hline Cord blood or bone marrow $(n=7)$ & $4(57.1)$ & \multirow[t]{2}{*}{0.414} & \multirow[t]{2}{*}{$2.00(0.37-11.1)$} \\
\hline Peripheral blood $(\mathrm{n}=33)$ & $24(72.7)$ & & \\
\hline \multicolumn{4}{|l|}{ Conditioning regimen } \\
\hline Reduced intensity $(n=16)$ & $9(56.3)$ & \multirow[t]{2}{*}{0.121} & \multirow[t]{2}{*}{$2.96(0.73-11.9)$} \\
\hline Myeloablative $(n=24)$ & $19(79.2)$ & & \\
\hline \multicolumn{4}{|l|}{ ATG } \\
\hline With $(n=19)$ & $11(57.9)$ & \multirow[t]{2}{*}{0.135} & \multirow[t]{2}{*}{$2.91(0.70-12.1)$} \\
\hline Without $(n=20)$ & $16(80.0)$ & & \\
\hline \multicolumn{4}{|l|}{ Donor } \\
\hline Related $(\mathrm{n}=19)$ & $11(57.9)$ & \multirow[t]{2}{*}{0.112} & \multirow[t]{2}{*}{$3.12(0.75-12.5)$} \\
\hline Unrelated $(\mathrm{n}=21)$ & $17(81.0)$ & & \\
\hline \multicolumn{4}{|l|}{ Acute GVHD } \\
\hline Absent $(n=19)$ & $11(57.9)$ & \multirow[t]{2}{*}{0.170} & \multirow[t]{2}{*}{$3.09(0.75-12.8)$} \\
\hline Present $(n=21)$ & $17(81.0)$ & & \\
\hline \multicolumn{4}{|l|}{ Age } \\
\hline$<20$ years old $(n=14)$ & $8(57.1)$ & \multirow[t]{2}{*}{0.173} & \multirow[t]{2}{*}{$2.50(0.62-10.1)$} \\
\hline$\geq 20$ years old $(n=26)$ & $20(76.9)$ & & \\
\hline$<35$ years old $(n=20)$ & $13(65.0)$ & \multirow[t]{2}{*}{0.366} & \multirow[t]{2}{*}{$1.61(0.41-6.34)$} \\
\hline$\geq 35$ years old $(n=20)$ & $15(75.0)$ & & \\
\hline
\end{tabular}

ATG, anti-thymocyte globulin; GVHD, graft-vs.-host disease; CI, confidence interval; OR, odds ratio; EBV, Epstein-Barr virus.

of the graft (15). This immunosuppression is associated with the occurrence of different events in the post-transplant period, such as development of GVHD, infections and PTLDs (16). Viral infections are a major concern in the subset of aHSCT, and while CMV infection has been consistently associated with a significant morbidity/mortality increase (17-19), EBV infection has been underestimated in these patients since only a minority will suffer from EBV-associated complications, such as PTLD $(11,13,20)$.

The incidence of EBV DNAemia varies within transplant centers, ranging from 0.1 to $63 \%(11,21,22)$. In our study, we verified that $70.0 \%$ of our patients were positive for EBV, at least once during the follow-up period, nevertheless the prevalence of EBV-positive patients at a specific time ranged from 25-58\%. Dumas et al, monitored EBV viral load at least once a week for 3 months and verified that EBV DNAemia occurred in approximately $14.0 \%$ of patients, which is significant lower than what we describe (23). Hence, these results show that there are significant differences amongst transplant centers that may be explored considering the individual characteristics of patients.

Literature refers that EBV infection is most common within the first 100 days post-transplant, in high-risk patients $(24,25)$. In our study, we describe that EBV infection varied throughout the follow-up period, with a mean of $65.6 \pm 39.6$ days (range, 27-183). According to the guidelines for diagnosis and monitoring of EBV DNAemia, the monitoring

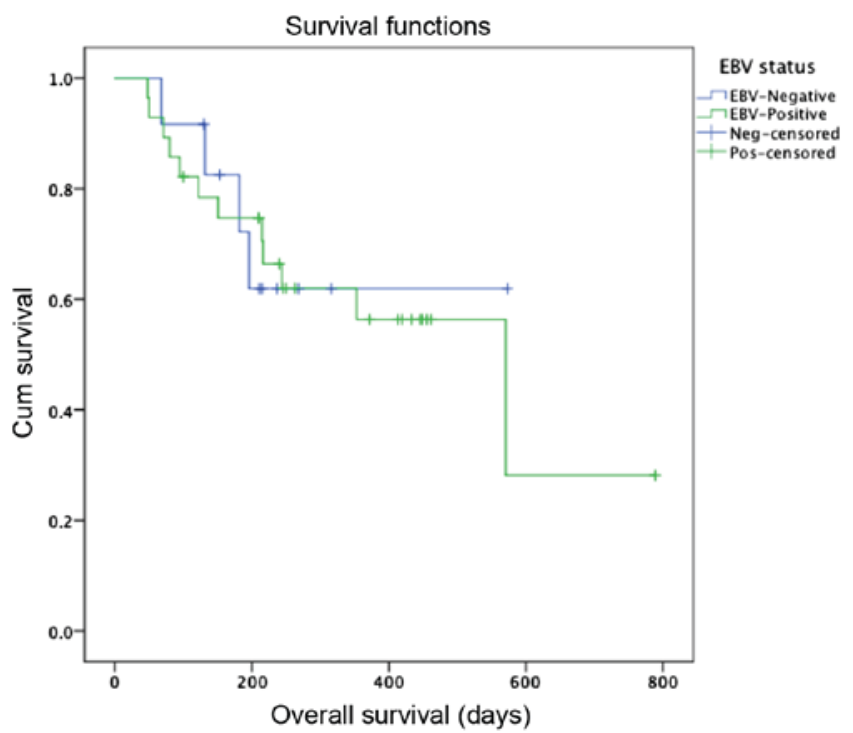

Figure 2. Kaplan-Meier plots with log-rank test estimate the post-transplant survival of aHSCT patients with and without EBV infection. aHSCT, allogeneic-hematopoietic stem cell transplant; EBV, Epstein-Barr virus.

should be performed by quantitative PCR and monitorization must start at the first month post-transplant, and should be performed at least during 4 months after transplantation, with 
A

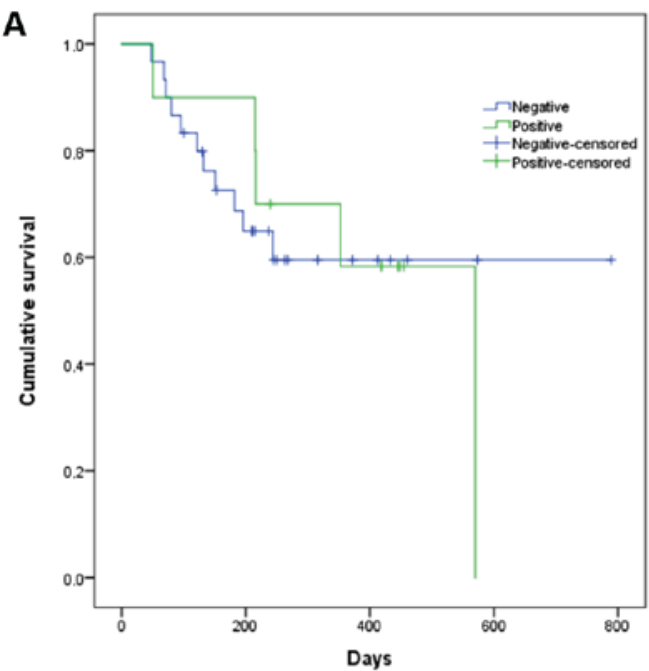

C

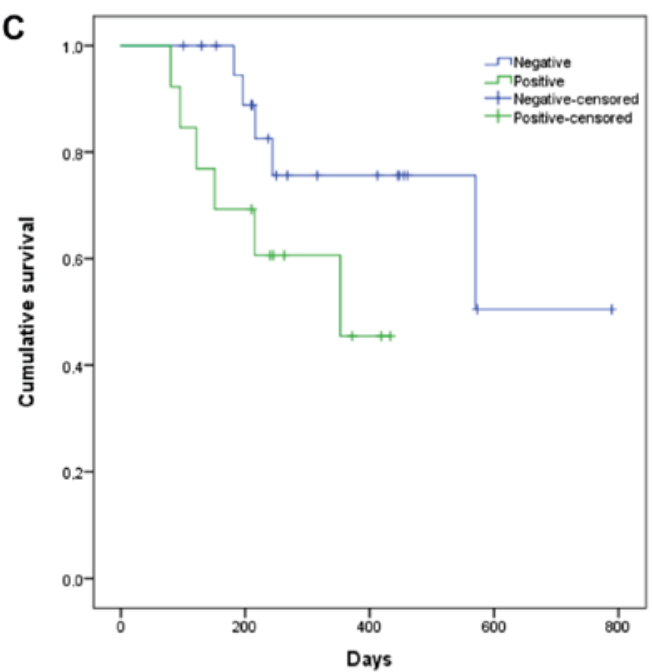

E

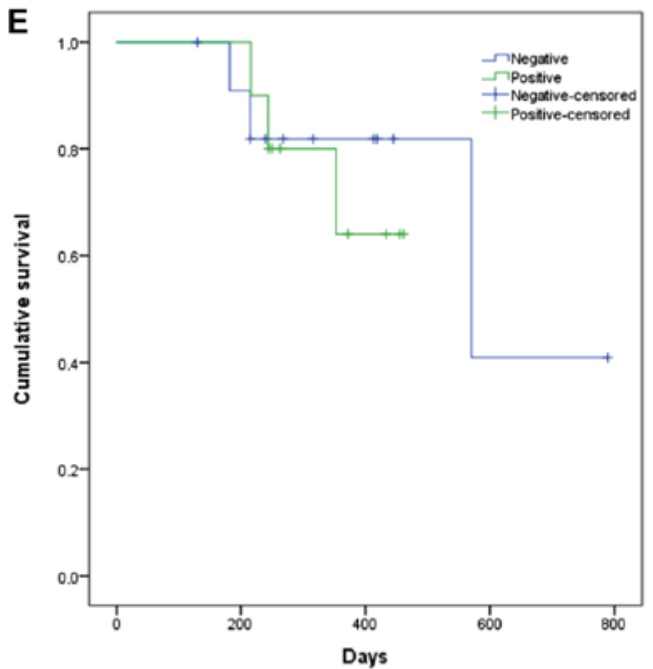

B
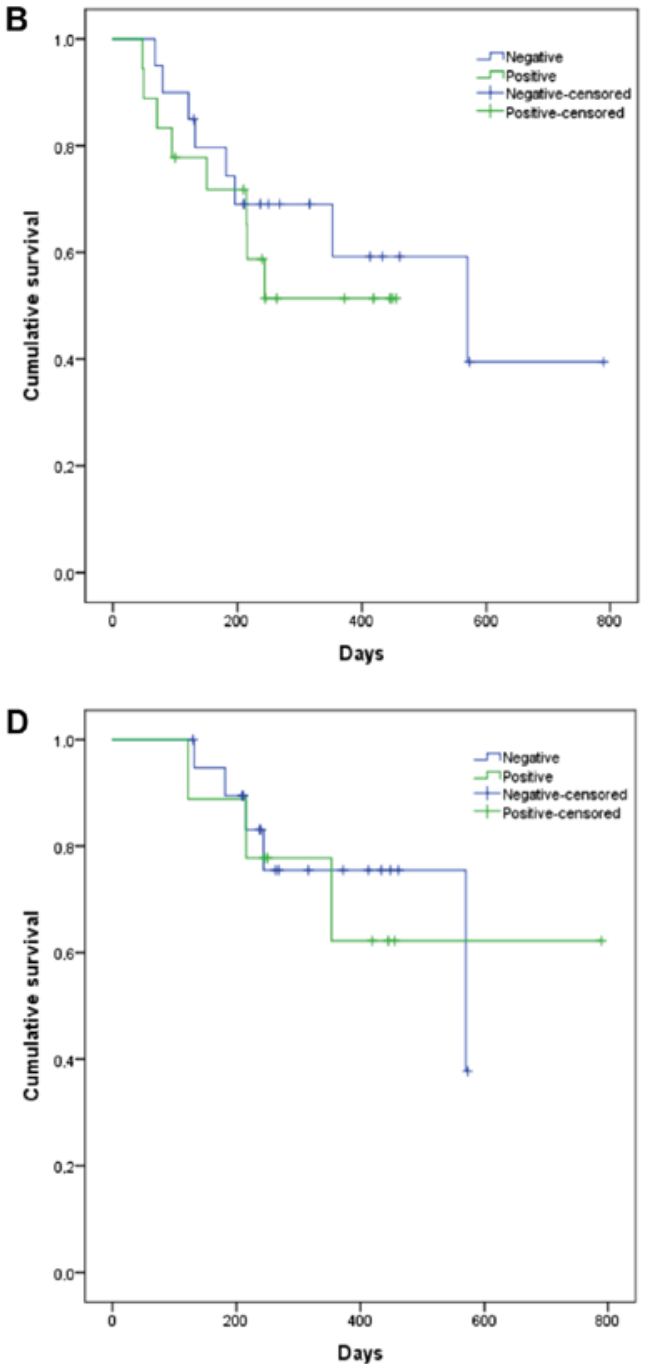

$\mathbf{F}$

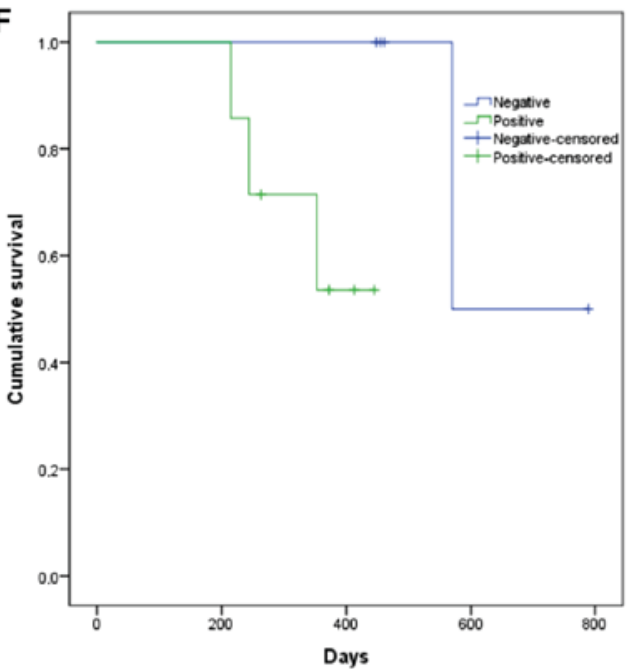

Figure 3. Kaplan-Meier plots with log-rank test estimate the post-transplant survival of aHSCT patients with and without EBV infection at the different times after transplantation. (A) D+30 post-transplant, (B) D+60 post-transplant, (C) D+90 post-transplant, (D) D+120 post-transplant, (E) D+150 post-transplant, and (F) D+180 days post-transplant. aHSCT, allogeneic-hematopoietic stem cell transplant; D, day; EBV, Epstein-Barr virus.

a weekly frequency $(11,12)$. Despite this, many authors discuss the cost-effectiveness of EBV monitoring once-a-week and therefore many studies are required to show what would be the best time and interval of monitoring. Moreover, EBV viral load has been having different input data since the cutoff viral loads for treatment are variable and the development of international standardization of EBV viral load management is yet to be defined $(12,13,26)$. Gulley and Tang, affirm that routine monitoring of EBV infection is viable in PTLD prevention, although further studies must be done to correlate specific viral 
loads in the identification of high-risk patients (27). As defined by published guidelines, rituximab therapy is used prophylactically before or shortly after transplant to reduce the risk of EBV DNAemia and PTLD development in high-risk patients, such as patients with EBV-seropositive donors (11). In these cases, viral load is also informative, when there is a withdrawal of immunosuppression, and rituximab administration, to verify if the treatment is being successful (27).

The identification of high-risk patients for EBV infection is crucial for the correct clinical approach of EBV-associated morbidity/mortality in aHSCT patients. Accessing variables associated with transplant, and complications associated with treatment, such as PTLD, include patients into two groups: High-risk and low-risk. High risk patients have pre-transplant risk factor such as T-cell depletion, EBV serology donor/recipient mismatched, cord blood transplantation, HLA mismatch, Splenectomy and second HSCT; and post-transplant risk factors as severe acute or cGVHD and high or rising EBV DNAemia $(11,13,25,28)$.

Our data showed that patients with unrelated and/or mismatched donors were more prone to develop an EBV infection post-transplant, and that using peripheral blood as source of stem cells adds a higher risk for EBV infection. Studies report EBV infections of $8.8 \%$ in MAC conditionings and $35.0 \%$ in RICs (29), $54.0 \%$ in T-cell depletion (30) and $65.0 \%$ in T-cell depletion concomitant with ATG use (22). Xuan et al showed that the use of ATG, HLA-mismatched, unrelated donor and acute aGVHD were identified as risk factors for EBV infection (4). These findings are according those reporting that intensified conditioning increase the incidence of EBV viremia and disease (4). In our study, myeloablation conditioning and use of ATG demonstrated a 3-times higher risk of developing EBV infection. ATG has been widely used to decrease the incidence of GVHD (31), however, because of T-cell depletion, ATG is also associated with relapse (32). The optimal dose of ATG depends on transplant characteristics, such as type of donor, and may range from 2.5 to $30 \mathrm{mg} / \mathrm{kg}$ (33). ATG has beneficial effects in preventing GVHD, although it delays immune reconstitution, promoting an increased risk of EBV reactivation, and potentially EBV-associated lymphoproliferative disease (34). Literature shows that higher doses of ATG seem to be related with PTLD development (35). Indeed, at our institution, no more than $10 \mathrm{mg} / \mathrm{kg}$ is used, and this may have contributed for the fact that no PTLD was observed in this cohort. When addressing the development of GVHD, we observed that patients who developed aGVHD, had 3-times increased association with EBV infection. Furthermore, we noticed that all patients with $\mathrm{CGVHD}$, were positive for EBV at least once in the post-transplant follow-up. As described previously by Janeczko et al, GVHD is related to delayed immune reconstitution, favoring infections in the early period post-transplant. Moreover, viral infections are also associated with delayed immune response and appear to be linked to the degree of immunosuppression (36).

Review of EBV infection on different periods post-transplant revealed that unrelated donor, myeloablation and the use of ATG seem to be risk factors for EBV infection occurrence at D+60; while GVHD is connected to EBV infection at D+90; and ATG, unrelated donor and GVHD are related to EBV infection at day $\mathrm{D}+150$. These results seem to corroborate the literature regarding the identification of high-risk markers for EBV infection. Furthermore, our study reports that EBV positivity at D+90 days and D+180 might be associated with increased mortality ( $\mathrm{P}=0.095,303.3$ vs. 593.2 days and $\mathrm{P}=0.097,367.0$ vs. 679.5 , respectively). We acknowledge that EBV infection is not, by itself, responsible for higher mortality rates, therefore further studies should be performed with more patients.

EBV infection is still a major concern in the subset of HSCT and these results showed that EBV routine monitoring is useful in high-risk patients during the first months after transplantation. In a previous study, the authors accessed the importance of EBV monitoring in patients submitted to aHSCT, regarding the development of PTLD (13). Although no patients of this study developed PTLD, it is still important performing EBV monitoring when several risk factors, are present. The implementation of guidelines and standardization of EBV monitorization in HSCT patients will contribute for the cost-effectiveness of this monitorization reducing unnecessary morbidity/mortality associated with EBV-infection.

\section{Acknowledgements}

The authors would like to acknowledge the support of Mrs. Rute Silva from the Bone Marrow Transplant Service at IPO Porto, who assisted the collection of clinic-pathological data for the present study.

\section{Funding}

Joana Marinho-Dias received a grant for the development of $\mathrm{PhD}$ from the Portuguese League Against Cancer (Liga Portuguesa Contra o Cancro-Núcleo Regional do Norte) between April and September 2016.

\section{Availability of data and materials}

The data obtained from the present study are part of the institution clinical records of patients and are not publicly available due to confidentiality but are available from the corresponding author on reasonable request.

\section{Authors' contributions}

JM-D, RM and HS designed the study. CP-V, LL, RB, FC and ACT collected and analyzed the clinical information of patients. IB and RM collaborated in viral detection and interpretation of results. JM-D and HS performed analysis of data, the draft of the manuscript and its final version. All authors were given the opportunity to revise the manuscript.

\section{Ethics approval and consent to participate}

The present study was approved by The Ethics Committee of Portuguese Oncology Institute of Porto and patients provided informed consent for enrollment in the study.

\section{Patient consent for publication}

Not applicable. 


\section{Competing interests}

The authors declare that they have no competing interests.

\section{References}

1. Howlader N, Noone AM, Krapcho M, Miller D, Bishop K Kosary CL, Yu M, Ruhl J, Tatalovich Z, Mariotto A, et al: SEER Cancer Statistics Review (CSR), 1975-2014. Nat Cancer Inst, Bethesda, MD, 2017.

2. Curtis RE, Travis LB, Rowlings PA, Socié G, Kingma DW Banks PM, Jaffe ES, Sale GE, Horowitz MM, Witherspoon RP, et al Risk of lymphoproliferative disorders after bone marrow transplantation: A multi-institutional study. Blood 94: 2208-2216, 1999.

3. Juric MK, Ghimire S, Ogonek J, Weissinger EM, Holler E, van Rood JJ, Oudshoorn M, Dickinson A and Greinix HT: Milestones of hematopoietic stem cell transplantation-from first human studies to current developments. Front Immunol 7: 470, 2016

4. Xuan L, Huang F, Fan Z, Zhou H, Zhang X, Yu G, Zhang Y, Liu C, Sun J and Liu Q: Effects of intensified conditioning on Epstein-Bar virus and cytomegalovirus infections in allogeneic hematopoietic stem cell transplantation for hematological malignancies. J Hematol Oncol 5: 46, 2012.

5. Fan J, Jing M, Yang M, Xu L, Liang H, Huang Y, Yang R, Gui G, Wang $\mathrm{H}$, Gong S, et al: Herpesvirus infections in hematopoietic stem cell transplant recipients seropositive for human cytomegalovirus before transplantation. Int J Infect Dis 46: 89-93, 2016.

6. Funke VA, Moreira MC and Vigorito AC: Acute and chronic Graft-versus-host disease after hematopoietic stem cell transplantation. Rev Assoc Med Bras (1992) 62 (Suppl 1): S44-S50, 2016.

7. Storek J, Mohty M and Boelens JJ: Rabbit anti-T cell globulin in allogeneic hematopoietic cell transplantation. Biol Blood Marrow Transplant 21: 959-970, 2015.

8. Styczynski J, Tridello G, Gil L, Ljungman P, Hoek J, Iacobelli S, Ward KN, Cordonnier C, Einsele H, Socie G, et al: Impact of donor Epstein-Barr virus serostatus on the incidence of graft-versus-host disease in patients with acute leukemia after hematopoietic stem-cell transplantation: A study from the acute leukemia and infectious diseases working parties of the European society for blood and marrow transplantation. J Clin Oncol 34: 2212-2220, 2016

9. Janani MK, Malathi J, Rela M, Farouk M, Padmapriya J and Madhavan HN: Genotypic detection of Epstein Barr virus in pediatric transplant recipients from India. Indian Pediatr 52: 946-950, 2015.

10. Styczynski J, Einsele H, Gil L and Ljungman P: Outcome of treatment of Epstein-Barr virus-related post-transplant lymphoproliferative disorder in hematopoietic stem cell recipients: A comprehensive review of reported cases. Transpl Infect Dis 11: 383-392, 2009

11. Styczynski J, van der Velden W, Fox CP, Engelhard D, de la Camara R, Cordonnier C, Ljungman P; Sixth European Conference on Infections in Leukemia, a joint venture of the Infectious Diseases Working Party of the European Society of Blood and Marrow Transplantation (EBMT-IDWP), the Infectious Diseases Group of the European Organization for Research and Treatment of Cancer (EORTC-IDG), the International Immunocompromised Host Society (ICHS) and the European Leukemia Net (ELN): Management of Epstein-Barr Virus infections and post-transplant lymphoproliferative disorders in patients after allogeneic hematopoietic stem cell transplantation: Sixth European Conference on Infections in Leukemia (ECIL-6) guidelines. Haematologica 101: 803-811, 2016.

12. Solano C, Mateo EM, Pérez A, Talaya A, Terol MJ, Albert E, Giménez E, Vinuesa V, Piñana JL, Boluda JCH and Navarro D: Epstein-Barr virus DNA load kinetics analysis in allogeneic hematopoietic stem cell transplant recipients: Is it of any clinical usefulness? J Clin Virol 97: 26-32, 2017.

13. Marinho-Dias J, Lobo J, Henrique H, et al: Post-transplant lymphoproliferative disease in hematopoietic stem cell transplant patients: A single center retrospective study between 2005 and 2012. Mol Med Rep (In press), 2018.

14. Marinho-Dias J and Sousa H: Cytomegalovirus infection and cervical cancer: From past doubts to present questions. Acta Med Port 26: 154-160, 2013.

15. Henig I and Zuckerman T: Hematopoietic stem cell transplantation-50 years of evolution and future perspectives. Rambam Maimonides Med J 5: e0028, 2014.
16. Al-Mansour Z, Nelson BP and Evens AM: Post-transplant lymphoproliferative disease (PTLD): Risk factors, diagnosis, and current treatment strategies. Curr Hematol Malig Rep 8: 173-183, 2013.

17. Sousa H, Boutolleau D, Ribeiro J, Teixeira AL, Pinho Vaz C, Campilho F, Branca R, Campos A Jr, Baldaque I and Medeiros R: Cytomegalovirus infection in patients who underwent allogeneic hematopoietic stem cell transplantation in Portugal: A five-year retrospective review. Biol Blood Marrow Transplant 20: 1958-1967, 2014

18. Campos AB, Ribeiro J, Boutolleau D and Sousa H: Human cytomegalovirus antiviral drug resistance in hematopoietic stem cell transplantation: Current state of the art. Rev Med Virol 26: 161-182, 2016.

19. Campos AB, Ribeiro J, Pinho Vaz C, Campilho F, Branca R, Campos A Jr, Baldaque I, Medeiros R, Boutolleau D and Sousa H: Genotypic resistance of cytomegalovirus to antivirals in hematopoietic stem cell transplant recipients from Portugal: A retrospective study. Antiviral Res 138: 86-92, 2017.

20. Preiksaitis JK: New developments in the diagnosis and management of posttransplantation lymphoproliferative disorders in solid organ transplant recipients. Clin Infect Dis 39: 1016-1023, 2004.

21. Blaes AH, Cao Q, Wagner JE, Young JA, Weisdorf DJ and Brunstein CG: Monitoring and preemptive rituximab therapy for Epstein-Barr virus reactivation after antithymocyte globulin containing nonmyeloablative conditioning for umbilical cord blood transplantation. Biol Blood Marrow Transplant 16: 287-291, 2010.

22. van Esser JW, van der Holt B, Meijer E, Niesters HG, Trenschel R, Thijsen SF, van Loon AM, Frassoni F, Bacigalupo A, Schaefer UW, et al: Epstein-Barr virus (EBV) reactivation is a frequent event after allogeneic stem cell transplantation (SCT) and quantitatively predicts EBV-lymphoproliferative disease following T-cell-depleted SCT. Blood 98: 972-978, 2001.

23. Dumas PY, Ruggeri A, Robin M, Crotta A, Abraham J, Forcade E, Bay JO, Michallet M, Bertrand Y, Socié G, et al: Incidence and risk factors of EBV reactivation after unrelated cord blood transplantation: A Eurocord and Société Française de Greffe de Moelle-Therapie Cellulaire collaborative study. Bone Marrow Transplant 48: 253-256, 2013.

24. Reddy N, Rezvani K, Barrett AJ and Savani BN: Strategies to prevent EBV reactivation and posttransplant lymphoproliferative disorders (PTLD) after allogeneic stem cell transplantation in high-risk patients. Biol Blood Marrow Transplant 17: 591-597, 2011.

25. Uhlin M, WikellH, Sundin M,Blennow O, Maeurer M, Ringden O, Winiarski J, Ljungman P, Remberger M and Mattsson J: Risk factors for Epstein-Barr virus-related post-transplant lymphoproliferative disease after allogeneic hematopoietic stem cell transplantation. Haematologica 99: 346-352, 2014.

26. Marques HH, Shikanai-Yasuda MA, dAzevedo LS, Caiaffa-Filho HH, Pierrotti LC, Aquino MZ, Lopes MH, Maluf NZ, Campos SV and Costa SF: Management of post-transplant Epstein-Barr virus-related lymphoproliferative disease in solid organ and hematopoietic stem cell recipients. Rev Soc Bras Med Trop 47: 543-546, 2014.

27. Gulley ML and Tang W: Using Epstein-Barr viral load assays to diagnose, monitor, and prevent posttransplant lymphoproliferative disorder. Clin Microbiol Rev 23: 350-366, 2010.

28. Bar-Natan M and Nagler A: Epstein-Barr virus-associated post-transplant lymphoproliferative disorder. Isr Med Assoc J 8: 205-207, 2006.

29. Cohen J, Gandhi M, Naik P, Cubitt D, Rao K, Thaker U, Davies EG, Gaspar HB, Amrolia PJ and Veys P: Increased incidence of EBV-related disease following paediatric stem cell transplantation with reduced-intensity conditioning. $\mathrm{Br} \mathrm{J}$ Haematol 129: 229-239, 2005.

30. van Esser JW, Niesters HG, van der Holt B, MeijerE, Osterhaus AD, Gratama JW, Verdonck LF, Löwenberg B and Cornelissen JJ: Prevention of Epstein-Barr virus-lymphoproliferative disease by molecular monitoring and preemptive rituximab in high-risk patients after allogeneic stem cell transplantation. Blood 99: 4364-4369, 2002

31. Dabas R, Lee R, Servito MT, Dharmani-Khan P, Modi M, van Slyke T, Luider J, Durand C, Larratt L, Brandwein J, et al: Antithymocyte globulin at clinically relevant concentrations kills leukemic blasts. Biol Blood Marrow Transplant 22: 815-824, 2016. 
32. Crocchiolo R, Esterni B, Castagna L, Fürst S, El-Cheikh J, Devillier R, Granata A, Oudin C, Calmels B, Chabannon C, et al: Two days of antithymocyte globulin are associated with a reduced incidence of acute and chronic graft-versus-host disease in reduced-intensity conditioning transplantation for hematologic diseases. Cancer 119: 986-992, 2013.

33. Bacigalupo A: ATG in allogeneic stem cell transplantation: Standard of care in 2017? Point? Blood Adv 1: 569-572, 2017.

34. Pidala J, Tomblyn M, Nishihori T, Ayala E, Field T, Fernandez H, Perez L, Locke F, Alsina M, Ochoa JL, et al: ATG prevents severe acute graft-versus-host disease in mismatched unrelated donor hematopoietic cell transplantation. Biol Blood Marrow Transplant 17: 1237-1244, 2011.
35. Podgorny PJ, Ugarte-Torres A, Liu Y, Williamson TS, Russell JA and Storek J: High rabbit-antihuman thymocyte globulin levels are associated with low likelihood of graft-vs-host disease and high likelihood of posttransplant lymphoproliferative disorder. Biol Blood Marrow Transplant 16: 915-926, 2010.

36. Janeczko M, Mielcarek M, Rybka B, Ryczan-Krawczyk R, Noworolska-Sauren D and Kałwak K: Immune recovery and the risk of CMV/ EBV reactivation in children post allogeneic haematopoietic stem cell transplantation. Cent Eur J Immunol 41: 287-296, 2016.

This work is licensed under a Creative Commons Attribution-NonCommercial-NoDerivatives 4.0 International (CC BY-NC-ND 4.0) License. 